\title{
Production of Hydroxylapatite from Biowaste, Chicken Manure by Hydrothermal Process
}

\author{
Sevgihan Yildiz Bircan $^{1 *}$, Ichiro Naruse ${ }^{2}$, Kozo Matsumoto $^{2}$, Kuniyuki Kitagawa ${ }^{2}$ \\ ${ }^{1}$ Department of Mechanical Science and Engineering, Graduate School of Engineering, Nagoya University, Nagoya, Japan \\ ${ }^{2}$ EcoTopia Science Institute, Nagoya University, Nagoya, Japan \\ Email: *sevgihan@gmail.com
}

Received January 28, 2013; revised March 3, 2013; accepted March 13, 2013

\begin{abstract}
Hydrothermal process has been applied for effective production of Hydrogen from biowastes. In this study hydrothermal process for production of valuable Hydroxylapatitefrom chicken manure containing phosphorus was focused on. Conditions of $400^{\circ} \mathrm{C}$ and $26-27 \mathrm{MPa}$ with addition of $1 \mathrm{mmol} \mathrm{Ca}(\mathrm{OH})_{2}$ were determined as the optimal by using Ophospho-DL-serine as a model compound. Afterwards, the real biowaste containing phosphorous, chicken manure was processed under the same conditions. Formation of a Hydroxylapatite; in the solid residue was confirmed from X-ray diffraction (XRD) patterns, after purification. It was found that $27.9 \%$ of $\mathrm{P}$ in the chicken manure was converted to Hydroxylapatite. With the use of acetic acid as a chemical purification medium, Hydroxylapatite was obtained.
\end{abstract}

Keywords: Hydrothermal Process; Biowaste; Chicken Manure; Hydroxylapatite

\section{Introduction}

Production of poultry is rapidly expanding worldwide to meet the needs of the increasing human population. This cause an increased poultry biowaste, i.e. chicken manure [1]. Pollutants from improperly managed chicken manure can cause serious environmental problems for water and air. The huge amount of waste produced in a concentrated area requires urgent treatment and disposal solutions because of gaseous pollutants of ammonia and $\mathrm{H} 2 \mathrm{~S}$ as well as green house gases of $\mathrm{CH}_{4}$ and $\mathrm{CO}_{2}$. Besides, improper use of chicken manure can result in pollution of soil and groundwater [2].

Valuable material, Hydroxylapatite is a calcium orthophosphate with chemical composition of $\mathrm{Ca}_{10}\left(\mathrm{PO}_{4}\right)_{6}(\mathrm{OH})_{2}$. There are chemical similarities between Hydroxyapatite and the mineral part of human bone. Therefore it is highly used for biomedical applications [3-5].

Catalysts were used to enhance the reaction rate of the hydrothermal process in sub or supercritical water at low reaction temperature [6]. The addition of catalysts could also enhance the Hydrogen yield. The effects of the $\mathrm{Na}_{2} \mathrm{CO}_{3}$ and $\mathrm{Ni}$ catalysts as additives on the hydrothermal process of cellulose at $400^{\circ} \mathrm{C}$ were reported [7]. The addition of the optimum amount of $\mathrm{Na}_{2} \mathrm{CO}_{3}$ increased Hydrogen yield and suppressed $\mathrm{CO} 2$ emission in the gas phase. Yanik et al. [8] reported that trona, red mud, $\mathrm{K}_{2} \mathrm{CO}_{3}$ and Raney-Ni were useful for lignocellulosic and proteinous

"Corresponding author. materials. Watanabe et al. [9] studied the effect of $\mathrm{ZrO}_{2}$ as a catalyst, and reported that for glucose and cellulose, the Hydrogen yield with $\mathrm{ZrO}_{2}$ was almost twice as much as without the catalyst.

In earlier study, various catalysts and additives used for hydrothermal process were studied and $\mathrm{Ca}(\mathrm{OH})_{2}$ was found to be a suitable additive because it could suppress the production of heteroatom pollutants in the gas phase and enhance the Hydrogen yield. $\mathrm{Ca}(\mathrm{OH})_{2}$ is also reasonable than other additives and catalysts currently available. The additive cost is an important factor for treatment of a large amount of biowaste [10].

First, selecting and using pure test samples of O-phospho-DL-serine with $\mathrm{P}$, as a model compound, the optimum conditions were determined for the hydrothermal process. Then, these conditions were applied to a real biowaste, chicken manure.

The objective of this study was providing production of Hydroxylapatite as a valuable material through the hydrothermal process by using biowaste, chicken manure with $\mathrm{Ca}(\mathrm{OH})_{2}$.

\section{Experimental}

\subsection{Experimental Setup}

The experimental setup is basically same as that reported the earlier study [10]. A reactor is a stainless steel (SUS 316 of $1 / 2$ inch in O.D. $12 \mathrm{~cm}$ in length) 1 ), connected to the T-fitting 2). A strain amplifier 3 ) for pressure meas- 
urement (Kyowa-Dengyo, Co., Japan) was connected to the T-fitting, and the stop valve 4) was connected to the other side. A gas chromatograph oven (Hewlett Packard, 5890 GC) was used for heating the reactor to a controlled temperature.

\subsection{Reagent}

O-phospho-DL-serine, $\mathrm{Ca}(\mathrm{OH})_{2}$ which was used as the additive is of analytical grade, acetic acid which was used in purification process, pure Hydroxylapatite, and $\mathrm{CaCO}_{3}$ were purchased from Wako Chemical Co. Ltd (Japan).

Commercially available chicken manure was purchased from G. I. Ltd. (Japan). The chicken manure's elemental compositions were $30.3 \% \mathrm{C}, 4.7 \% \mathrm{H}, 2.6 \% \mathrm{~N}$, $0.8 \% \mathrm{~S}, 4.4 \% \mathrm{~K}[10]$.

\subsection{Procedure}

About $400 \mathrm{mg}$ sample was put into the reactortogether with $1 \mathrm{mmol} \mathrm{Ca}(\mathrm{OH})_{2}$ and $5 \mathrm{ml}$ water. Then, $\mathrm{N}_{2}$ gas was introduced to purge the residual $\mathrm{O}_{2}$ gas in the reactor. The reactor was put in the ovenand heated to $400^{\circ} \mathrm{C}$ at $1.5^{\circ} \mathrm{C} \mathrm{min}{ }^{-1}$. The reactor was maintained at $400^{\circ} \mathrm{C}$ for 40 minutes to complete the hydrothermal process under the pressure of $26-27 \mathrm{MPa}$. Then, the oven was cooled down to $30^{\circ} \mathrm{C}$. And the generated components were analyzed.

\subsection{Analytical Equipment}

Ionic chemical species dissolved in the liquid phase were analyzed with an ion chromatograph (HIC-SP Suppressor Ion Chromatograph, Shimadzu). The parameters and conditions; Shimadzu IC-SC-1 Column for Cation $(+)$, Shodex ICSI-50 Column for Anion (-), Oxalic acid 3.0 $\mathrm{mM}$ Mobile phase for Cation $(+), \mathrm{Na}_{2} \mathrm{CO}_{3} 3.2 \mathrm{mM}$ and $\mathrm{NaHCO}_{3} 1.0 \mathrm{mM}$ Mobile phase for Anion (-), 1.5 $\mathrm{mLmin}^{-1}$ flow for $(+)$ Cation and Anion $(-), 40^{\circ} \mathrm{C}$ column temperature for Cation $(+), 25^{\circ} \mathrm{C}$ column temperature for Anion $(-)$ were used for the IC [10].

An XRD system (RINT 2500/PC by Rigaku Co., Japan) was used for identification of residual solid samples. The diffraction data were collected from $20^{\circ}$ to $60^{\circ}$ in $2 \theta$ values with a step of $0.02^{\circ}$. An elemental analyzer (Perkin Elmer 2400 Series II CHNS/O System) was used for determination of $\mathrm{C}, \mathrm{H}$, and $\mathrm{N}$.

The resulting gaseous components were analyzed using a gas chromatograph (GC Shimadzu 5A) equipped with a thermal conductivity detector (TCD).

Porapak Q (length: $2 \mathrm{~m}$, diameter: $3 \mathrm{~mm}$ ) Column, Argon carrier gas, $98 \mathrm{kPa}$ inlet pressure, $80^{\circ} \mathrm{C}$ inlet temperature and $50^{\circ} \mathrm{C}$ column temperature were used for $\mathrm{H}_{2}$ analysis as the parameters and conditions [10].
Porapak Q (length: $2 \mathrm{~m}$, diameter: $3 \mathrm{~mm}$ ) Column, Helium carrier gas, $170 \mathrm{kPa}$ inlet pressure, $80^{\circ} \mathrm{C}$ inlet temperature and $50^{\circ} \mathrm{C}$ column temperature were used for $\mathrm{CH}_{4}, \mathrm{CO}$, etc. analysis as the parameters and conditions [10].

\subsection{Purification of Solid Residue (Hydroxylapatite) by Chemical Method}

Acetic acid solution was usedas weak acidfor purification of Hydroxylapatite.

\section{Results and Discussion}

\subsection{Hydrothermal Process of O-Phospho-DL-Serine}

\subsubsection{Liquid Phases}

In the earlier paper, the effect of added $\mathrm{Ca}(\mathrm{OH})_{2}$ amount on the concentration of phosphate ion dissolved in the liquid phase for O-phospho-DL-serine was reported [10].

The temperature for the hydrothermal process was held at $400^{\circ} \mathrm{C}$, without the additive, $93.3 \%$ of sample phosphorus was converted to phosphate ion. As the amount of $\mathrm{Ca}(\mathrm{OH})_{2}$ was increased, the phosphate ion yield was suppressed [10].

\subsubsection{Solid Phases}

Figure 1 shows the XRD patterns of pure Hydroxylapatite (a) and crude residue from O-phospho-DL-serine with the different amounts of $\mathrm{Ca}(\mathrm{OH})_{2}$. With $1 \mathrm{mmol} \mathrm{Ca}(\mathrm{OH})_{2}$ (b), the similar pattern tothat ofHydroxylapatite is observed. With $2 \mathrm{mmol} \mathrm{Ca}(\mathrm{OH})_{2}$ (c), some peaks of Hydroxylapatite is recognized together with the $\mathrm{CaCO}_{3}$ peaks. With $3 \mathrm{mmol} \mathrm{Ca}(\mathrm{OH})_{2}(\mathrm{~d})$ stronger of Hydroxylapatite peaks became weaker while the peaks of $\mathrm{Ca}(\mathrm{OH})_{2}$ and $\mathrm{CaCO}_{3}$.

\subsection{Hydrothermal Process of Biowaste Chicken Manure}

Figure 2 shows the effect of additive on the yields of various gases generated through a hydrothermal process by using chicken manure at $400^{\circ} \mathrm{C}$. Alkaline additive provide significant changes in yields. Hydrogen gas was found to be produced mainly in the gas phase. $\mathrm{H}_{2}$ yields were increased and other gasses were suppressed by using additive, especially for $\mathrm{CO}_{2}$, which was suppressed very effectively.

The optimal conditions for the hydrothermal process $\left(400^{\circ} \mathrm{C}\right.$ and $\left.1 \mathrm{mmol} \mathrm{Ca}(\mathrm{OH})_{2}\right)$ found for the model sample were applied to the chicken manure sample for production of Hydroxylapatite.

Four hundred $\mathrm{mg}$ of chicken manure and $1 \mathrm{mmol}$ $\mathrm{Ca}(\mathrm{OH})_{2}$ were processed (Figure 3). Hydroxylapatite and $\mathrm{CaCO}_{3}$ were identified for the resulting. The equilib- 


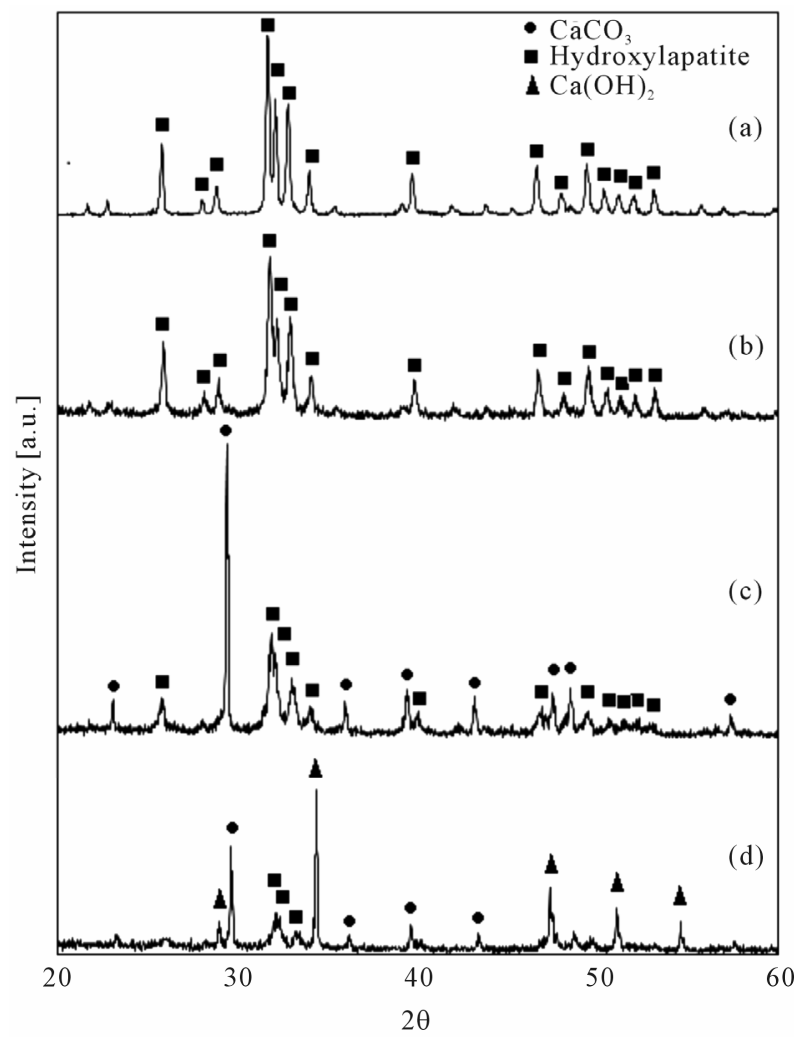

Figure 1. XRD patterns of pure Hydroxylapatite (a); O-Phospho-DL-serine with $1 \mathrm{mmol} \mathrm{Ca}(\mathrm{OH})_{2}$ (b); O-Phospho-DLserine with $2 \mathrm{mmol} \mathrm{Ca}(\mathrm{OH})_{2}$ (c); O-Phospho-DL-serine with $3 \mathrm{mmol} \mathrm{Ca}(\mathrm{OH})_{2}$ (d).

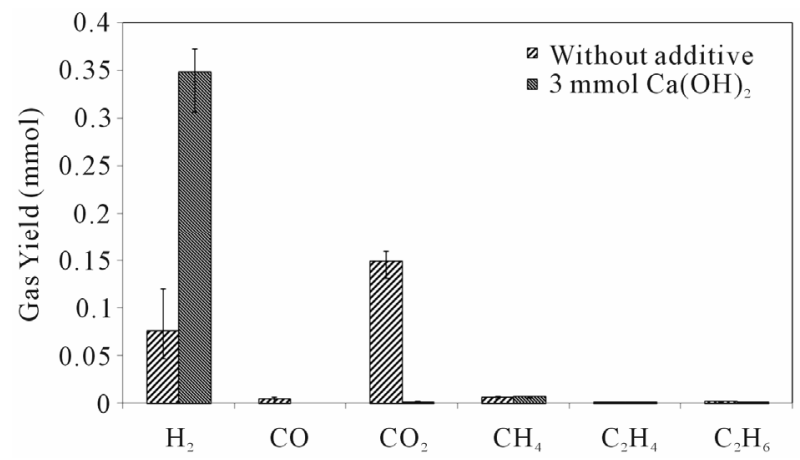

Figure 2. Effect of additive amount on the yields of various gases at $400^{\circ} \mathrm{C}$ (chicken manure).

rium (1) shows oxidation of sample with water. The equilibrium (2) showsthe main gasification of water-gas shift reactions. Thereaction (3) indicates the reaction of Hydroxylapatite. Phosphate ions in chicken manure were transferred to Hydroxylapatite through the hydrothermal process. Hydrogen and $\mathrm{CO}_{2}$ were produced because of water shift reactions. The equilibrium (4) shows suppression of $\mathrm{CO}_{2}$. And also it shows production of $\mathrm{CaCO}_{3}$, which is detected on the XRD patterns.

$$
\text { Organic } \mathrm{C}+\mathrm{H}_{2} \mathrm{O} \leftrightarrows \mathrm{CO}+\mathrm{H}_{2}
$$

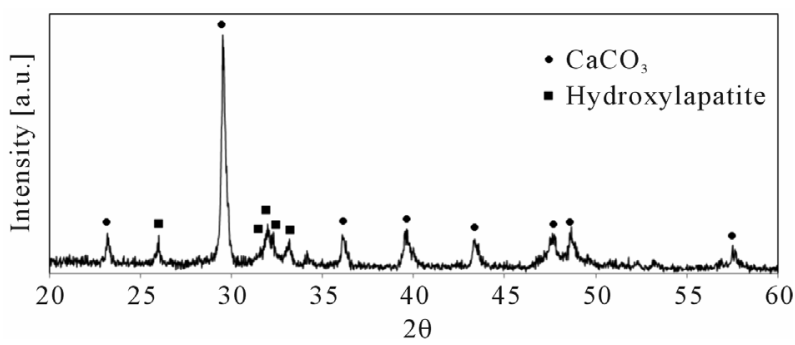

Figure 3. XRD patterns of $400 \mathrm{mg}$ chicken manure with 1 $\mathrm{mmol} \mathrm{Ca}(\mathrm{OH})_{2}$ (before acetic acid purification).

$$
\begin{gathered}
\mathrm{H}_{2} \mathrm{O}+\mathrm{CO} \leftrightarrows \mathrm{CO}_{2}+\mathrm{H}_{2} \\
\text { Organic } \mathrm{P} \stackrel{\mathrm{H}_{2} \mathrm{O}}{\longrightarrow} \mathrm{PO}_{4}^{3-} \rightarrow \mathrm{Ca}_{10}\left(\mathrm{PO}_{4}\right)_{6}(\mathrm{OH})_{2} \\
\mathrm{Ca}(\mathrm{OH})_{2}+\mathrm{CO}_{2} \leftrightarrows \mathrm{CaCO}_{3}+\mathrm{H}_{2} \mathrm{O}
\end{gathered}
$$

For purification of crude Hydroxylapatite, acetic acid was used. The reaction (5) shows the purification reaction. The crude residue contains Hydroxylapatite and $\mathrm{CaCO}_{3}$ as the major components.

Figure 4 shows XRD patterns of Sample 1 (20\% Hydroxylapatite $+80 \% \mathrm{CaCO}_{3}$ ) (before purification) (a), Sample $2\left(20 \%\right.$ Hydroxylapatite $\left.+80 \% \mathrm{CaCO}_{3}\right)$ (after purification) (b), pure Hydroxylapatite (100\% Hydroxylapatite), which were usedfor validation of purification. These samples prepared by using pure Hydroxylapatite and $\mathrm{CaCO}_{3}$, which were purchased from Wako Chemical Co. Ltd. (Japan). It shows that after $10 \%$ acetic acid solution for $5 \mathrm{~min}, 20 \%$ Hydroxylapatite was become pure HA.

Acetic acid reacted with calcium carbonate to give calcium acetate, water and carbon dioxide and not with Hydroxylapatite. Carbon dioxide evolved as a gas. The solid Hydroxylapatite can be separated fromthe $\mathrm{Ca}\left(\mathrm{CH}_{3} \mathrm{COO}\right)_{2}$ solution by filtration.

$$
\begin{aligned}
& \mathrm{Ca}_{5}\left(\mathrm{PO}_{4}\right)_{3}(\mathrm{OH})+\mathrm{CaCO}_{3}+2 \mathrm{CH}_{3} \mathrm{COOH} \\
& \rightarrow \mathrm{Ca}_{5}\left(\mathrm{PO}_{4}\right)_{3}(\mathrm{OH})+\mathrm{Ca}(\mathrm{CH} 3 \mathrm{COO})_{2}+\mathrm{H}_{2} \mathrm{O}+\mathrm{CO}_{2}
\end{aligned}
$$

Afterwards the solid residue of the chicken manure was purified by using 10\% acetic acid solution. Figure 5 shows the XRD patterns of the purified solid residues (a) and Hydroxylapatite (b).

Figure 5 shows a XRD peak at about $31.78^{\circ}(2 \theta)$ indicating Hydroxylapatite [11], and the accompanying two peaks at $32.18^{\circ}$ and $32.90^{\circ}$ were detected. The patterns confirm that the phosphorous atom in the sample was converted into the valuable compound, Hydroxylapatite, through the hydrothermal process. About 27.92\% of the $\mathrm{P}$ in the chicken manure was converted to Hydroxylapatite.

\section{Conclusions}

O-phospho-DL-serine was used as a model test sample to 


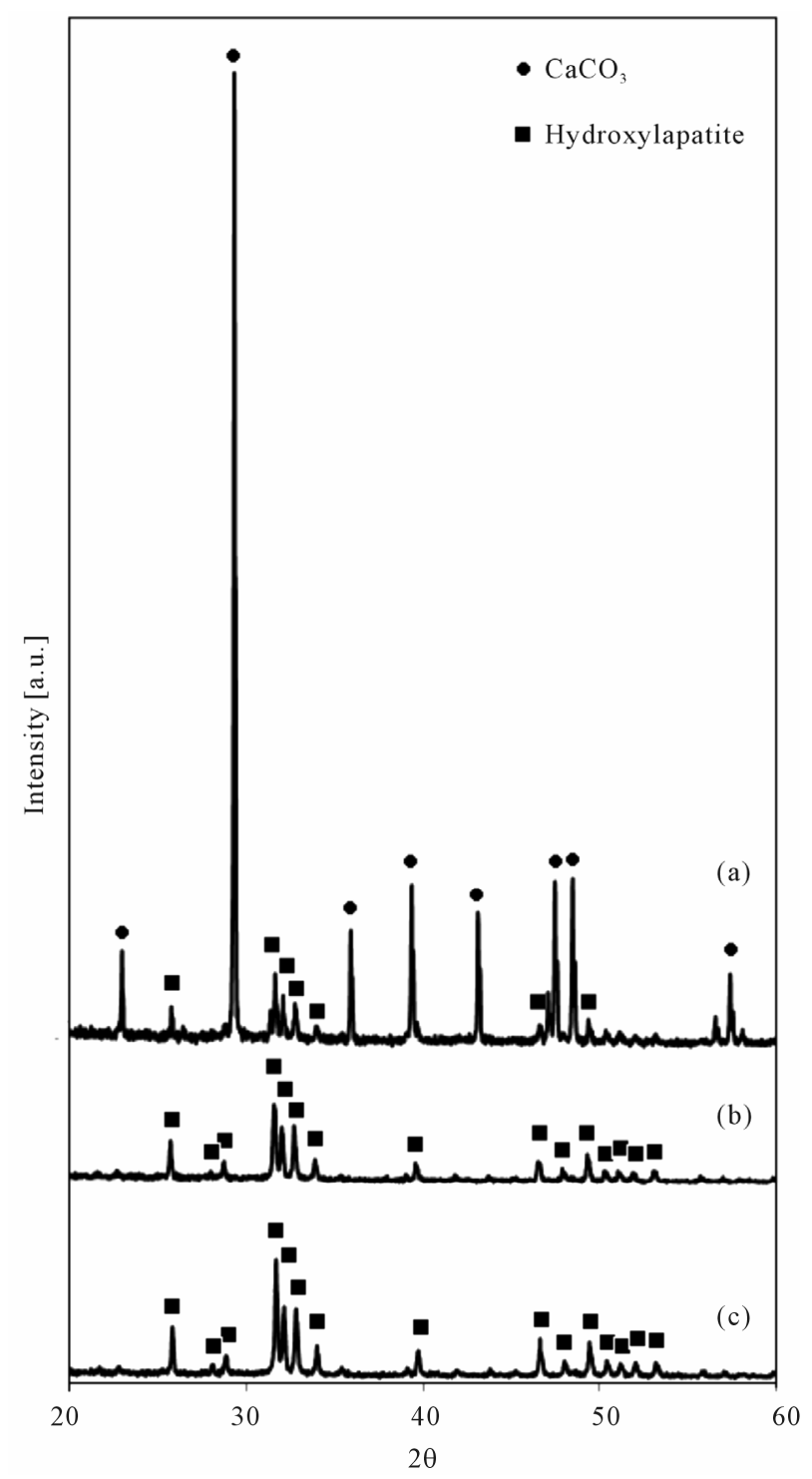

Figure 4. XRD patterns of Sample 1 (20\% Hydroxylapatite + $80 \% \mathrm{CaCO}_{3}$ ) (before purification) (a); Sample 2 (20\% Hydroxylapatite $+80 \% \mathrm{CaCO}_{3}$ ) (after purification) (b); pure Hydroxylapatite (100\% Hydroxylapatite) (c).

determine the optimum conditions of the hydrothermal process to produce Hydroxylapatite. Under these same optimum conditions (i.e. the reaction temperature of $400^{\circ} \mathrm{C}$, use of $1 \mathrm{mmol} \mathrm{Ca}(\mathrm{OH})_{2}$ additive, and a reaction time of $40 \mathrm{~min}$ ), with sample of biowaste, chicken manure containing 9\% (wt/wt) phosphorus, the pure Hydroxylapatite was obtained in the purified solid phase. About 27.9\% of the phosphorus in the chicken manure was converted into Hydroxylapatite through the hydrothermal process.

The crude sample contained impurity such as $\mathrm{CaCO}_{3}$. However, by use of chemical purification method, the impurities could be removed. A new method was proposed for synthesizing of pure Hydroxylapatite by hydrothermal process of chicken manure.

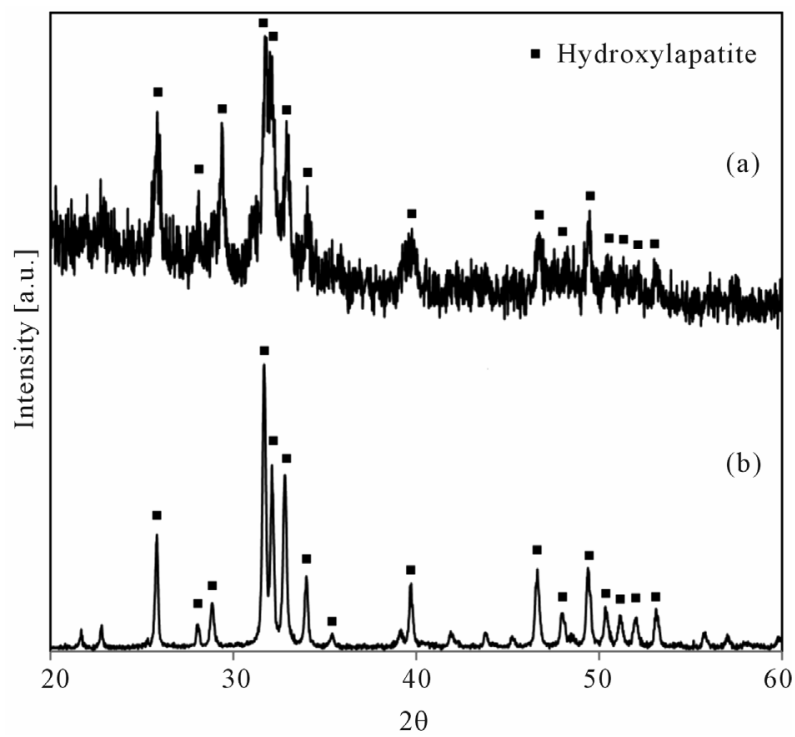

Figure 5. XRD patterns of purified sample (400 mg chicken manure with $\left.1 \mathrm{mmol} \mathrm{Ca}(\mathrm{OH})_{2}\right)(a)$; and Hydroxylapatite (b).

External thermal energy is required for the hydrothermal process. However, the temperature used in this experiment was about $400^{\circ} \mathrm{C}$, which is not an extremely high temperature, and is available as industrial waste heat. This process would therefore represent a useful conversion of waste heat to Hydrogen and Hydroxylapatite.

\section{REFERENCES}

[1] R. C. Axtell, "Poultry Integrated Pest Management: Status and Future," Integrated Pest Management Reviews, Vol. 4, No. 1, 1999, pp. 53-73. doi:10.1023/A:1009637116897

[2] K. Yetilmezsoy and K. Sakar, "Development of Empirical Models for Performance Evaluation of UASB Reactors Treating Poultry Manure Wastewater under Different Operational Conditions," Journal of Hazardous Materials, Vol. 153, No. 1, 2008, pp. 532-543. doi:10.1016/j.jhazmat.2007.08.087

[3] M. Ozawa, K. Satake and R. Suzuki, "Removal of Aqueous Chromium by Fish Bone Waste Originated Hydroxyapatite," Journal of Materials Science Letters, Vol. 22, No. 7, 2003, pp. 513-514. doi:10.1023/A:1022982218727

[4] K. Byrappa and T. Ohachi, "Crystal Growth Technology," William Andrew Publishing, New York, pp. 525-526.

[5] A. Jillavenkatesa and R. A. Condrate, "Sol-Gel Processing of Hydroxyapatite," Journal of Materials Science, Vol. 33, No. 16, 1998, pp. 4111-4119. doi:10.1023/A:1004436732282

[6] Y. Matsumura, T. Minowa, B. Potic, S. R. A. Kersten, W. Prins, W. P. M. van Swaaij, B. van de Beld, D. C. Elliott, G. G. Neuenschwander, A. Kruse Jr. and M. J. Antal, "Biomass Gasification in Near- and Super-Critical Water: Status and Prospects," Biomass and Bioenergy, Vol. 29, No. 4, 2005, pp. 269-292. 
doi:10.1016/j.biombioe.2005.04.006

[7] Y. Ishida, K. Kumabe, K. Hata, K. Tanifuji, T. Hasegawa, K. Kitagawa, N. Isu, Y. Funahashi and T. Asai, "Selective Hydrogen Generation from Real Biomass through Hydrothermal Reaction at Relatively Low Temperatures," Biomass and Bioenergy, Vol. 33, No. 1, 2009, pp. 8-13. doi:10.1016/j.biombioe.2008.04.004

[8] J. Yanik, S. Ebale, A. Kruse, M. Saglam and M. Yuksel, "Biomass Gasification in Supercritical Water: II. Effect of Catalyst," International Journal of Hydrogen Energy, Vol. 33, No. 17, 2008, pp. 4520-4526. doi:10.1016/j.ijhydene.2008.06.024

[9] M. Watanabe, H. Inomata and K. Arai, "Catalytic Hydrogen Generation from Biomass (Glucose and Cellulose) with $\mathrm{ZrO}_{2}$ in Supercritical Water," Biomass and Bioenergy, Vol. 22, No. 5, 2002, pp. 405-410. doi:10.1016/S0961-9534(02)00017-X

[10] S. Yildiz Bircan, H. Kamoshita, R. Kanamori, Y. Ishida, K. Matsumoto, Y. Hasegawa and K. Kitagawa, "Behavior of Heteroatom Compounds in Hydrothermal Process of Biowaste for Hydrogen Production," Applied Energy, Vol. 88, No. 12, 2011, pp. 4874-4878. doi:10.1016/j.apenergy.2011.06.031

[11] U. Vijayalakshmi and S. Rajeswari, "Preparation and Characterization of Microcrystalline Hydroxyapatite Using Sol Gel Method," Trends in Biomaterials and Artificial Organs, Vol. 19, No. 2, 2006, pp. 57-62. 